\title{
Everybody loves field trips...but how do you assess them?
}

\author{
Daphene Cyr \& Laura Lucas \\ Indiana University-Purdue University at Indianapolis (IUPUI)
}

\begin{abstract}
In a technology school, the emphasis is on hands on, real life, practical applications of learning. One way to accomplish this is the use of field trips to reinforce classroom teaching. Students love to leave the classroom, and teachers appreciate a break from lecturing. But with the current emphasis on assessment and proof of student learning, the dilemma is how to prove the benefit of field trips to the students and perhaps more importantly to the industry partner that facilitates the field trip.
\end{abstract}

We can now tell you the answers for the pertinent questions of:

Does student learning improve with field trips?

Is there a better way to focus student learning while participating in field trips?

How do you document the learning from field trips?

Can you prove to industry the value of their participation?

And the short answer is that if you approach field trips with the same assessment based mindset as with classroom instruction you can implement and measure immense improvements in student learning. Furthermore, if you apply this same assessment attitude toward the industry partner you can also make the benefits more apparent to them.

In essence, preparation for student learning for field trips should follow the same assessment based preparation used for a regular class teaching, practicing, testing and then improving towards a formulated learning objective. The field trip can become a valuable tool by utilizing the additional senses of smell, hearing, touching uniquely that can enhance the field trip to gather and observe the information needed to truly understand the material presented. This methodology would apply to assessing the success of the experience to the Industry partner.

To reinforce and standardize this methodology we have developed departmental checklist and forms for faculty, students and the industry partner. By using both the methodology and forms everyone has consistent expectations and a higher level of success in meeting the goals of all participants. 


\section{Significance}

During the accreditation of the Construction Technology Department (CNT) at Indianapolis University - Purdue University Indianapolis (IUPUI) by the Technology Accreditation Commission of Accreditation Board of Engineering and Technology (TAC/ABET) in 2001, there was a concern about the evaluation of field trips. The assessment team did not believe that the field trip was an important aspect in the program due to the lack of actual documentation as proof of learning. But the faculty and students had many enlightening experiences, which facilitated their understanding of the technical concepts initially taught in the classroom. So, the research began to create a methodology that could be used to assess a field trip. The guidelines for field trip and assessment shown illustrate the historical practices of field trips, give a generic outline applicable to any subject and demonstrate implementation concepts for future field trips.

\section{Historical Research}

Experience shows us that preplanning is an important factor in having success on field trips ${ }^{1}$. Traditional field trips started in grade school with a visit to the local zoo or museum. The original idea of preplanning for a traditional field trip was to ensure that all paperwork was complete for the student and that copies of all signed permission slips, in case of an accident, were completed. Although the field trips were the best part of the class, teachers had a hard time justifying the outcomes. One example of how an outcomes-based teaching approach applied a field trip is by outlining the goals before the field trip. ${ }^{2}$

A junior high school teacher escorted many students and faculty to a viewing of the movie, The Titanic. Some of the items, which were outlined for learning, were as follows:

1. Students in math course could understand the calculations that twenty lifeboats would not fit 2,227 passengers and crew.

2. Social Studies teachers can show that a ticket in first class is very different from the third class quarters when traveling abroad.

3. Science students can observe the laws of Newton as they apply to forward movement $^{2}$.

This demonstrates the use of one field trip to cover dissimilar objectives by preplanning and guiding students into the specific objectives. Like any lesson, the teacher is more prepared when the experience has been previewed.

Another example of the cross curriculum comes from a school that wanted to integrate the problem solving aspect of science into the math and technology courses. This was a more realistic approach to how the students would use the math and technology to solve science problems in real-life ${ }^{3}$. To get the students interested in science they began using a park to investigate different aspects of science. One activity was as simple as the students using different senses to collect information about their surroundings. They could feel the heat of the sun or smell the scent of pine trees or hear the birds. This experience resulted in a larger understanding by the students and a better experience from the teachers. Then the aspect of measuring the heat of the 
sun or using probes to collect data linked the math and technology into the science to help the students understand the usefulness of all the topics to one another.

This was a planned experience incorporating teachers in different areas, but ran smoothly through the arrangement and preparation of the experience with the help of outside sources to moderate meetings. The teachers appreciated the guidance to take the education of the students to a new level that facilitated the students learning to a greater level of understanding.

Trying to be more scientific about the analysis of field trips, one study tried to control aspects of the field trips. This study believed that getting the most from field trips was done by preparatory lessons ${ }^{4}$. The students were broken into 3 groups:

1. Hands-on activities related to the field trip

2. Instruction on the field trip, but no hands on

3. No preparation, similar to the most traditional field trip.

Upon completion of the field trip, the students were tested on the subject matter and objectives that were arranged. The students with hands-on preparation had higher performance when they were tested on the field trip materials.

Faculty preparation for field trips should be no different than their preparation for a regular class. The advantages of imparting information through touch, sound, smell, time and two way interaction should be the enticement of field trips, not just a way to get out of teaching that day. This is especially useful for understanding construction because the materials are altered so much from delivery on site to the inclusion in a finished assembly. Construction is a process and as such it is crucial that students understand it from the unloading of bulk shipments of materials, through the cutting and adjustments of the assembly process through to the cleaning and prepping of the final product. It is even more important to customize the learning objectives and prepare materials for a field trip that reflect the uniquely obtainable observations available on site. Focusing the learning objectives per each course based on the unique aspects of each site visit can allow the same visit to serve several courses.

Manufacturing is another example of how the students can learn more by seeing the facility. A national curriculum for middle and high school students began in 1994 to introduce students to the modern factory ${ }^{5}$. Teachers were introduced to the program through a video professionally produced by a television station. It set up teacher workshops and had interviews with the companies to learn how to prepare student's visits. Teachers in social studies, science, communication skills and career training shared materials. One field trip could cover these crosscurricular areas to make the most of the event.

Using a residential construction site for several courses in a construction technology curriculum can focus on the unique aspects of site visits such as the smells of cut wood, the sounds of several work crews working together, the coordinating of labor needed to combine and create accurate assemblies of the raw materials, the management issues of coordinating separate work crews who all want to be in the same room at the same time. Seeing the house in different stages can assist 
the students of drawing classes visualize the wall sections or enhance the ability of students in the quality survey course as they estimate the parts. Other media such as video clips and movies can only come close to imparting information about sounds and perhaps even how long it really takes to do something, and material samples or scale models can address the issues of touch or the physical characteristics of individual components and are very useful in the teaching and practice phase of preparing the students for the field trip. But only actual site visits can bring all the observations and all the senses together at once.

Perhaps most importantly, a jobsite can adjust the experience to reflect the level of understanding of the students by utilizing "what if " scenarios to show students the many ways of getting to the same end point. Especially with the participation of the industry sponsor, students can be shown the effects of reversing the order of installation of certain components or see how often the pieces of the construction puzzle don't fit as well in certain situations. Often on the same job site we see several variations of the same floor plan that differed in material on the elevations. You can rewind or slow motion video clips, but photos don't easily indicate the order of assembly or actual time needed that is so easily demonstrated with on site visits. Videos can't relate the physical sensations attributed to being on site during situations of pouring rain or sudden winds that can turn a construction site dangerous.

Implementation in the fall of 2001, the authors began experimenting with how field trips could be assessed. Two courses were used to test the field trip models. Both courses utilize the field trip as a major learning activity in understanding the topics of the course. The following steps outline the process for successfully assessing a field trip. The course used as an example in the outline is ART 165, Construction Methods and Materials. This is an introductory course which covers the major materials types used in construction; soil, masonry, concrete, wood, and steel and how they utilized in construction system just as you would in a class arrangement.

1. Prepare a field trip outline of learning objectives and outcomes.

Prepare an outline for the learning objectives and learning outcomes for your field trip. Given examples found in research and experiences from courses in progress, the hope is that this outline can be used as a tool to guide courses that use field trips to enhance the objective of the course. A formative evaluation model was used to establish an assessment loop; teach, practice, test and improve, as follows.

Overall course-learning objectives for ART 165 include the understanding of these for each chapter. The student should be able to complete the following objectives on each material type:

a. Identify the different characteristics of construction materials.

b. Define and explain construction materials and their uses.

c. Recognize and give explanations of different construction systems.

d. Possess a basic knowledge of the construction process. 
2. Pre-field for the trip by teaching in class.

Research has shown that the preplanning of the field trips was the most important aspect. One way of beginning this process is having the students take a pretest of the important information. This gives a baseline for the students to see the areas that they need to pay attention. The pretest questions follow the students throughout the unit. Sample questions pertaining to the area of wood construction is:

a. Describe a sill plate detail - how are the foundation supports and anchors the structure?

b. What is used in this house, anchor bolts or straps? How is this is part of above item? What is the spacing of anchor system?

c. Is something used to seal between sill plate and foundation wall?

d. What is used for the floor joist - dimension lumber $(2 \mathrm{x})$ or I-joist or 'engineered truss'?

e. What supports floor joists in crawl space or basement? What is the size of beam?

f. Do you see any 'joist hangers'?

Establish a specific learning objective derived from information available uniquely from the field situation. The learning objective here is to improve the observation skills of the students. In a specific construction context, in fact, to teach them to utilize more of their cognitive information processing senses. Taking advantage of the uniqueness of field trips to stimulate the senses of smell, sound, touch, the passage of time, as well as the more often utilized sense of seeing. Some of the students might already understand the terminology of wood structures, but those who lack that experience can use the text to supplement their knowledge, before attempting to identify the pieces during the field trip.

3. Practice focusing on the learning objectives to prepare for the field trip.

This would be the traditional training portion of the course. The chapters of the text are reviewed, worksheets may be done in class, videos could be shown as examples of explaining the specific items. Make sure the students are prepared to focus on the learning objectives developed and by the use of a pretest or list of learning points to "forewarn" the students about what they need to be observant about. This could include videos to show them what to expect, a handout of lists of key objects to find, photos or drawings to labels etc. This could also mean running mock "seek and find" missions within the classroom or lab. This is our favorite way to practice observation skills. 
Another part of the preparation is to ask the students to research the field trip. They should know about the company that they would visit. What size of company, how many employees, what kinds of workers, etc. This increases the students' interest of the actual location. Most field trip locations are examples of where the student might someday work. They can get a sense of where their degree can take them and why the basic course information is important. The technology of today allows the students to actually prepare for the experience ${ }^{6}$.

In addition to preparing the students, the industrial representative for the field trip host company should also have the learning objectives. In the example of the residential field trip, the company was asked to have an introduction and history to their company along with the ability to show the students different stages of a house being built. The tour guide has the same list of questions that the students are required to answer so that the tour includes all the aspects and terminology of residential building. The outline helps the industry spokesperson organize their thoughts and talk to the desired outcomes. We find that they prefer this structured method rather than the alternative of hoping student participation generates the appropriate information.

4. Attending the actual field trip.

With all of the scheduling and review of information completed during the class before the field trip, it should run smoothly. The students and the host speaker have predetermined goals and the course instructor becomes more of an observer with little participation needed. Everyone knows why he or she is there and what information needs to be collected during the visit. With the communication prior to the field trip, the host person is aware of student requirements. Students are given ownership to be responsible for having their questions answered. Many times a field trip can be difficult for everyone to hear the speaker. A construction site, for example, can be noisy due to large equipment operating. Also, there are sometimes small areas on the trip where not everyone can enter at the same time. Giving the students and the leader the questions, informs every one of expectations. From experience during two semesters of field trips, I have found that the students asking questions encourage the industrial partner, which further expands their interest. It seems that they don't mind asking the same question more that once because they are proud of their business and appreciate that the student wants to get all of the details correct.

It is always required to remind the students to be professional and respect the leaders. To act interested and wear proper clothing. Usually hard soled shoes and long pants are required for a construction job site. Everyone should meet at one location prior to beginning the field trip.

\section{Post field trip test.}

Provide a means for the students to prove their understanding of the information gathered during the observation in the field. This may mean taking the "test" version of the pretest (or portions of it), it may mean essays or journal entries, or the use of digital cameras to capture images later used to identify the process, procedure or materials as seen on the field trip. This is also where for the benefit of the Industry partner; the students are "tested" against the objectives of the hosting company. 
ART 165 requires that the students write a critique of the field trip including good and bad points and suggestions for future visits. Remembering the name of the host, what favorable or unfavorable impressions. Would you want to work there? A packet of information is gathered for each field trip. It includes their preview of the company, their notes which were taken during the visit and the critique. The students have been allowed to use this information for a field trip portion of the exam. They answer specific short essay type questions. The packets and this portion of the exam are turned in before they begin on the next portion of the exam which is not specific to the field trip, but rather assessing the overall understanding of the topic.

These were turned in as homework. The chapter test also included questions specific to the field trip, taken from the list of objectives that were covered during the visit. ART 155 not only included the use of portions of the field trip as assignments, but the final project for the course is a house plan which would include the parts that were investigated during the site tour.

6. Improve student learning through assessment.

Explanation to the students of the correct response to the test is crucial to their ability to get it right next time. Not only are the correct responses explained but also the best manner to collect or understand the information is presented. Focus is on the student improving their process of observation as well as the learning of the actual information. Many of the upper level lab courses in our program require labs where observation and deduction processes are crucial to passing the class.

In the Department of Construction Technology our assessment efforts begin with the application of the Teach, Practice, Test and Improve axiom of student learning. This has been working well in our classrooms and was expected to bring an easily replicable methodology to planning and executing our field trip experiences. Although the process is useful for specific learning objectives, as it is repeated from course to course that in a sense is the practice component and the improvements show up in with the student success in their subsequent courses

From the Industry perspective the most obvious learning objective is that the students know more about the hosting company perhaps in a long term sense, think favorably of them and maybe come work for them in the future. On another level the industry partners want to make a difference in the learning experience of the students, perhaps they are exposing the students to the real life aspects of construction that they wish they had experience in their school days. Individual companies will have their own viewpoints, and the process of developing a relationship and following these steps would enhance the experience for them. A well-run field trip experience is crucial for continued participation and for increasing participation by local companies.

Implementation

Over the past two semesters, the implementation of this process has been defined and utilized. The checklist below is one result.

ART 165 Materials and Methods: required course, 2 sections aprox 60 students a semester 
a. Identify Industry partners from faculty contacts or Advisory Boards or even from employers of our students

b. Contact by phone and by sending out invitations

c. Follow-up contact and decide on a specific time and place

d. Develop and understanding of Industry learning objectives

e. Share faculty learning objectives and preparation material with students and industry

f. Faculty teaches and prepares students for field trip

g. Conduct field trip

h. Test for student learning

i. Assess student learning for improvement

j. Contact Industry and share results (include thank you letter)

k. Faculty and Industry share improvement ideas

Future impact

Over the course of two semesters in three courses CNT 105, ART 155, ART 165, the authors began instituting the procedures and assessment methods as described in this paper to investigate and document the benefits of field trips on all parties involved. Many improvements in student learning were immediately apparent, while the benefits to the industry partners were more long term in nature. The ability to have multiple sections of a class using different instructors are becoming more harmonious in procedures and learning outcomes. With documented assessment information about the benefits of field trips, and pre-developed guides and instructional materials, all faculty became more involved and thus more field trips were taken.

A benefit to be further researched and developed if the ability to develop teaching and learning materials that so well define the instructional objectives and outcomes of a field trip that students could self direct their own field trips. This would be especially beneficial to online and distant learning situations. With the structured field trip, it could be possible to have students made individual observations on sites, complete their questions and have online discussions to practice the learning outcomes. Technology is giving us the advantage of digital images that could be studied online and in person. New virtual field trips are being developed constantly with books like New Virtual Field Trips published last year that includes links to all new resources ${ }^{7}$. The discovery of the sites can also be a learning experience for the students that they can share with others $^{8}$. Creating your own Internet field trip may define the areas of instruction that are specific to one student's needs.

Summary

We believe that by successfully documenting the affects of field trips for both students and Industry (as well as faculty) we will be able to convince more faculty and industry partners to participate in them.... That the logistical headaches of setting up field trips would be overweighed by the benefits to all of having them, and that in today's competition for the involvement of industry partners, they are more likely to participate with the to faculty and students from 


\section{University programs with the proven successful methodologies}

\section{References}

1. Siegal. A. (1999). How to avoid field trip foul-ups. Principal 78 (4). 72-3.

2. Savage, M. (1999). Outcomes-based teaching - - Oh, that sinking feeling. The Clearing House 73(1). 11-12.

3. Heflich, D., Dixon, J., \& Davis, K. (2001). Taking it to the field: The authentic integration of mathematics and technology in inquiry-based science instruction. Journal of Computers in Mathematics and Science Teaching 20(1), 99112 .

4. Bracey, G. (1995). Getting the most from field trips. Phi Delta Kappan 76. 567.

5. Donlevy, J. \& Donlevy, T. (2000) What's up in factories?: Introducing teachers and students to the dynamic world of modern manufacturing. International Journal of Instructional Media 27(1). 21-4.

6. Cox-Peterson, A.M. \& Melber, L.M. (2001) Using technology to prepare and extend field trips. The Clearing House75 (1). $18-20$.

7. Cooper G. \& Cooper G. (2001) New Virtual Field Trips. Englewood, CO. Libraries Unlimited.

8. Stevenson, S. (2001). Discover and create your own field trips. Multimedia Schools (8) 4. 40 -5.

DAPHENE CYR, Assistant Professor in Construction Technology in the Purdue School of Engineering \& Technology at IUPUI. B.S. of Building Construction Management, M.S. of Technology with an emphasis on Construction and Curriculum Development and PhD in Education (2002) from Purdue University, West Lafayette campus. Industrial experience from 1990 - 1997 in Houston, TX and 8 years mechanical experience in Indiana.

LAURA LUCAS Lecturer of Architectural Technology in the Purdue School of Engineeing \& Technology at IUPUI. B.S. of Architecture, Ball State University, MBA - Management, Indiana University. Over 20 years of industrial experience in design through construction. Member of ASEE, and is a registered Architect in Indiana. Faculty Fellow 6r the Frontiers in Ed Conf. in 1999, and earned the William P. Jungclaus II Award for teaching excellence 2001. 